\title{
Effects of $\mathrm{NH}_{3}$ Plasma and Mg Doping on InGaZnO pH Sensing Membrane
}

\author{
Chyuan-Haur Kao ${ }^{1,2,3}{ }^{\oplus}$, Chia-Shao Liu ${ }^{1}$, Shih-Ming Chan ${ }^{4}$, Chih-Chen Kuo ${ }^{4}$, Shang-Che Tsai ${ }^{4}$, \\ Ming-Ling Lee ${ }^{5, *}$ and Hsiang Chen ${ }^{4, *} *$ (D)
}

1 Department of Electronic Engineering, Chang Gung University, 259 Wen-Hwa 1st Road, Kwei-Shan, Taoyuan 333, Taiwan; chkao@mail.cgu.edu.tw (C.-H.K.); chkao@mail.cgu.edu (C.-S.L.)

2 Kidney Research Center, Department of Nephrology, Chang Gung Memorial Hospital, Chang Gung University, No.5, Fuxing St., Guishan Township, Taoyuan 333, Taiwan

3 Department of Electronic Engineering, Ming Chi University of Technology, 284 Gungjuan Rd., Taishan Dist., New Taipei City 24301, Taiwan

4 Department of Applied Materials and Optoelectronic Engineering, National Chi Nan University, Puli, Nantou 545, Taiwan; s107328009@mail1.ncnu.edu.tw (S.-M.C.); s107328003@mail1.ncnu.edu.tw (C.-C.K.); s1063280042@mail1.ncnu.edu.tw (S.-C.T.)

5 Department of Electro-Optical Engineering, Minghsin University of Science and Technology, No.1, Xinxing Road, Xinfeng, Hsinchu 304, Taiwan

* Correspondence: mingling@must.edu.tw (M.-L.L.); hchen@ncnu.edu.tw (H.C.)

check for updates

Citation: Kao, C.-H.; Liu, C.-S.; Chan, S.-M.; Kuo, C.-C.; Tsai, S.-C.; Lee, M.-L.; Chen, H. Effects of $\mathrm{NH}_{3}$ Plasma and $\mathrm{Mg}$ Doping on InGaZnO pH Sensing Membrane. Membranes 2021, 11, 994. https://doi.org/ 10.3390/membranes11120994

Academic Editor: Feng-Tso Chien

Received: 20 November 2021 Accepted: 13 December 2021 Published: 20 December 2021

Publisher's Note: MDPI stays neutral with regard to jurisdictional claims in published maps and institutional affiliations.

Copyright: (c) 2021 by the authors. Licensee MDPI, Basel, Switzerland. This article is an open access article distributed under the terms and conditions of the Creative Commons Attribution (CC BY) license (https:/ / creativecommons.org/licenses/by/ $4.0 /)$.

\begin{abstract}
In this study, the effects of magnesium $(\mathrm{Mg})$ doping and Ammonia $\left(\mathrm{NH}_{3}\right)$ plasma on the $\mathrm{pH}$ sensing capabilities of InGaZnO membranes were investigated. Undoped InGaZnO and Mg-doped $\mathrm{pH}$ sensing membranes with $\mathrm{NH}_{3}$ plasma were examined with multiple material analyses including $\mathrm{X}$-ray diffraction, $\mathrm{X}$-ray photoelectron spectroscopy, secondary ion mass spectroscopy and transmission electron microscope, and $\mathrm{pH}$ sensing behaviors of the membrane in electrolyte-insulatorsemiconductors. Results indicate that $\mathrm{Mg}$ doping and $\mathrm{NH}_{3}$ plasma treatment could superpositionally enhance crystallization in fine nanostructures, and strengthen chemical bindings. Results indicate these material improvements increased $\mathrm{pH}$ sensing capability significantly. Plasma-treated Mg-doped InGaZnO $\mathrm{pH}$ sensing membranes show promise for future $\mathrm{pH}$ sensing biosensors.
\end{abstract}

Keywords: indium gallium zinc oxide; magnesium doped; membranes; sputtering; ammonia plasma treatment; $\mathrm{pH}$ sensing; biosensors

\section{Introduction}

The ion sensitive field-effect transistor (ISFET) with a sensing membrane for use in biosensing applications was demonstrated by P. Bergveld in 1970 [1]. When integrated with complementary metal oxide semiconductor technology, ISFETs are capable of detecting ion activity in the human body [2]. Concentrations of biologically related ions such $\mathrm{H}^{+}, \mathrm{Na}^{+}$, and $\mathrm{K}^{+}$are important health indexes associated with disease monitoring. Recently, various high-k dielectrics such as $\mathrm{Ta}_{2} \mathrm{O}_{5}$ [3], $\mathrm{Pr}_{2} \mathrm{O}_{3}$ [4], and $\mathrm{Er}_{2} \mathrm{O}_{3}$ [5] have been proposed as sensing membrane materials to detect these crucial ions in the human body [6,7]. To further enhance ion-sensing capabilities, it is worthwhile to explore materials, alternative fabrication processes, and treatments such as addition of nanoparticles or modulation of the membrane thickness [8,9]. In addition, incorporating post treatments such as Magnesium (Mg) doping and ammonia $\left(\mathrm{NH}_{3}\right)$ plasma treatment may optimize the membrane performance $[7,10,11]$. In this study, InGaZnO films, which can function as a transparent conductive oxide, have been demonstrated as ion-sensing membranes in electrolyte-insulator-semiconductor (EIS) structures. Furthermore, magnesium atoms were doped into InGaZnO films and $\mathrm{NH}_{3}$ plasma treatment was incorporated into the membrane fabrication process [12,13] to boost ion-sensing behavior. Based on previous studies $[10,14,15]$, magnesium atoms can fill in vacancies and reduce dangling bonds, and $\mathrm{NH}_{3}$ plasma treatment can include $\mathrm{N}$ atoms into 
the membrane to mitigate defects. Therefore, combination of $\mathrm{Mg}$ doping and $\mathrm{NH}_{3}$ plasma treatment may effectively improve material quality and ion-sensing capability [13]. To examine an InGaZnO membrane with these treatments, multiple material characterization techniques were performed, and sensing behaviors were evaluated $[16,17]$. To observe the morphologies both on the surface and in the cross section, scanning electron microscopy (SEM), atomic force microscopy (AFM), and transmission electron microscopy (TEM) images were taken. X-ray diffraction (XRD) was used to monitor crystalline structures, X-ray photoelectron spectroscopy (XPS) was used to study chemical bindings, and secondary ion mass spectrometry (SIMS) was used to evaluate element composition along the depth. Results indicate that $\mathrm{Mg}$ doping and $\mathrm{NH}_{3}$ plasma treatment could include both $\mathrm{Mg}$ and $\mathrm{N}$ atoms into the membrane to reinforce the chemical binding and strengthen crystallization [18]. Notably, AFM and SEM images revealed grainization on the membrane surface, and TEM images indicated passivation of cracks and separation lines in the cross section.

Consistent with material improvements, $\mathrm{pH}$ sensing capability was enhanced, and hysteresis voltage and drift rate were suppressed with the incorporation of $\mathrm{Mg}$ doping and NH3 plasma treatment in the membrane fabrication process $[19,20]$. This study confirms that incorporation of $\mathrm{Mg}$ doping and $\mathrm{NH} 3$ plasma treatment can work together to optimize membrane material properties and sensing performance [21,22]. Furthermore, based our previous study [23], appropriate annealing could effective improve the material quality and sensing behaviors. In this study, different from the annealing treatment, compared with the as-deposited samples, NH3 plasma treatment could boost InGaZnO samples with or without $\mathrm{Mg}$ doping in terms of sensing capability more effectively. Therefore, $\mathrm{NH} 3$ plasma treatment in this study is more favorable than annealing treatment in terms of improving the $\mathrm{pH}$ sensing behaviors. InGaZnO membranes with $\mathrm{Mg}$ doping and $\mathrm{NH} 3$ plasma treatment can achieve excellent sensing performance and are promising for fabrication of future portable biosensing devices [24].

\section{Experimental}

To fabricate InGaZnO sensing membranes on electrolyte-insulator-semiconductor structures, the structure was deposited on 4-inch n-type (100) silicon wafers with resistivity of 5-10 $\Omega$-cm [25]. To remove any native oxide, the wafers were cleaned using $\mathrm{HF}\left(\mathrm{HF}: \mathrm{H}_{2} \mathrm{O}=1: 100\right.$ ). Next, $50-\mathrm{nm} \mathrm{SiO}_{2}$ was grown by thermal wet oxidation. In our experiment, InGaZnO and $\mathrm{Mg}$ targets were purchased from Gredmann Company, Taiwan. Then, in the condition, 50-nm InGaZnO was deposited on the wafer by radio frequency (RF) reactive sputtering with a mixture of $\mathrm{Ar}$ and $\mathrm{O}_{2}\left(\mathrm{Ar}: \mathrm{O}_{2}=23: 2\right)$ ambient during sputtering [23]. In the second condition, a 50-nm Mg-doped InGaZnO sensing membrane was deposited by co-sputtering on the wafer. During the reactive sputtering, InGaZnO and $\mathrm{Mg}$ targets were used in an ambient of $\mathrm{Ar}: \mathrm{O}_{2}$ at 23:2 with RF power at $80 \mathrm{~W}$ and ambient pressure of $1.3 \mathrm{~Pa}$. Both undoped and $\mathrm{Mg}$-doped samples were subjected to a post- $\mathrm{NH}_{3}$ plasma treatment in a plasma-enhanced chemical vapor deposition (PECVD) system with an RF power of $30 \mathrm{~W}$ for $1 \mathrm{~min}$ and $3 \mathrm{~min}$, respectively. The $\mathrm{NH}_{3}$ plasma treatment was performed by a PECVD and the model and make of the PECVD was Sancom and PD-240. $\mathrm{An} \mathrm{Al} \mathrm{film} 300 \mathrm{~nm}$ in thickness was then deposited on the backside of the wafer. Next, adhesive silicone gel was used to define a sensing window. Finally, the samples were fabricated in silver gel on the copper lines of a printed circuit board. An epoxy package was used to separate the EIS structure and the copper lines. Since the EIS structure is not stable because defects between interface layer and silicon. To overcome the problem, incorporation of $\mathrm{NH}_{3}$ plasma treatement were used to optimize the sensing performance. The detailed fabrication process is illustrated in Figure 1. 


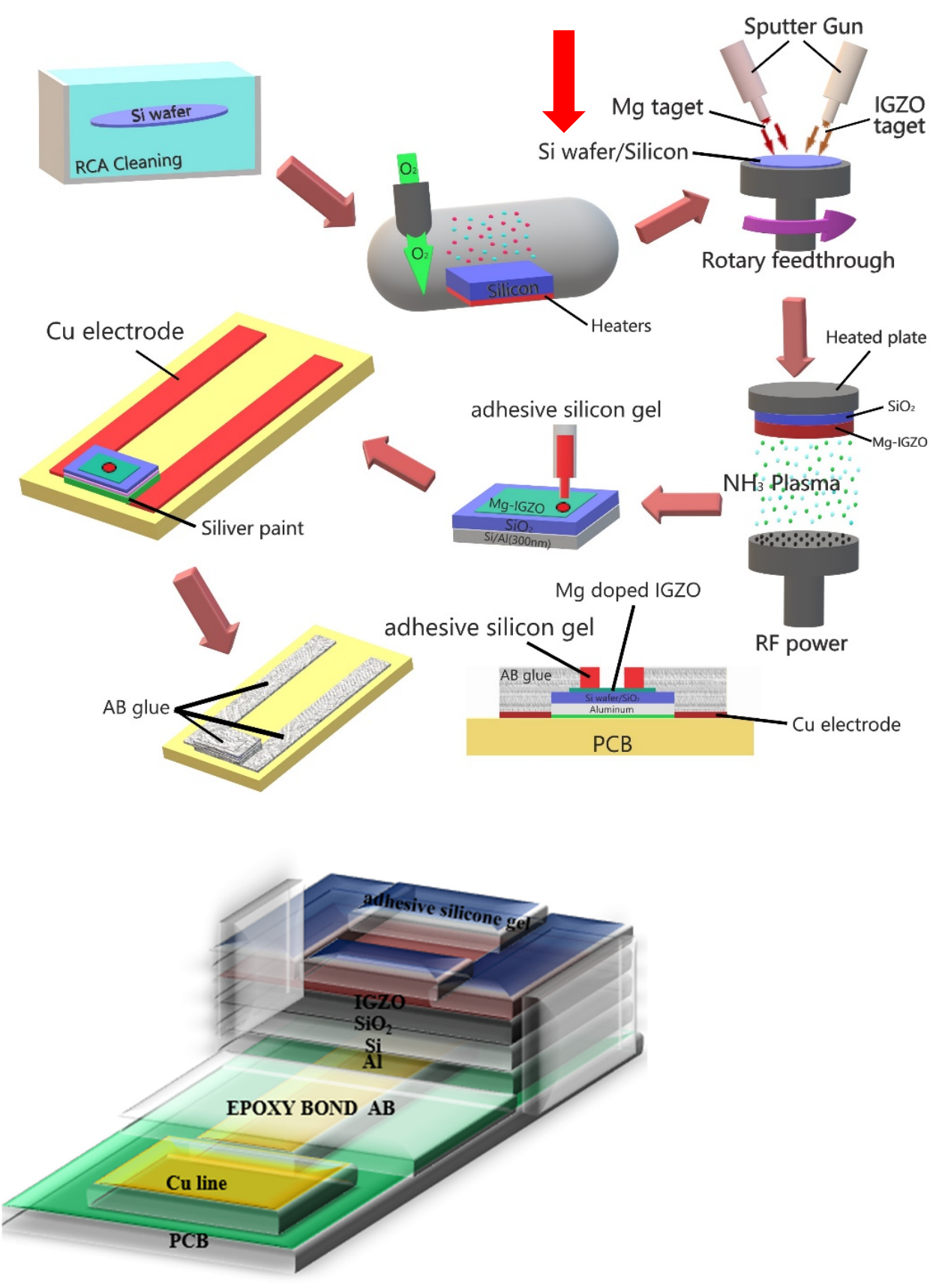

Figure 1. Schematic diagram of fabrication processes of $\mathrm{Mg}$ doped IGZO membranes with $\mathrm{NH}_{3}$ plasma treatment in EIS structures.

To evaluate the sensing behavior of a membrane, the ionic consumption reactions between the solution/sensing membrane can be explained by the site-binding model [26-28]. The voltage of the surface potential $(\psi)$ depends on the $\mathrm{pH}$ concentration of the electrolyte and the sensing factor $\beta$. The value of $(\psi)$ can be figured out using Equation (1).

$$
\psi=2.303 \frac{k T}{q} \frac{\beta}{\beta+1}(p H p z c-p H)
$$

( $k$ is Boltzmann's constant, $T$ is the temperature, $q$ is the elementary charge, $p H_{p z c}$ is the $p H$ value with no charge). $\beta$ is a factor related to the sensitivity of the gate membrane. Furthermore, the $\beta$ is linked to the density of surface hydroxyl groups, as described in 
Equation (2). $N_{S}$ is the number of surface site/area and $C_{D L}$ is the double layer capacitance based on the Gouy-Chapman-Stern model [29].

$$
\beta=\frac{2 q^{2} N_{s} \sqrt{K_{a} K_{b}}}{k T C_{D L}}
$$

To analyze the membrane films, multiple material analyzing techniques are performed. The make and model of SEM and TEM are JEOL JSM-7500F and JEOL JEM 2100 PLUS, respectively. The operating voltages for SEM and TEM were $15 \mathrm{kV}$ and $200 \mathrm{kV}$, respectively. In addition, the make and model of PL is HITACHI F-4500. The excitation laser wavelength was $325 \mathrm{~nm}$ with a laser spot diameter of $1 \mu \mathrm{m}$. The PL spectral range was 330 1000 nm (CCD sensor) and 1000 1500 nm (InGaAs sensor). As for the XRD apparatus, the make and model is Bruker D8 Discover. For XRD analysis of the samples, the grazing incidence of $\mathrm{X}$-ray beam CuKa $(k=1.542 \AA)$ radiation is used with an incidence angle step of $0.5^{\circ}$ in the diffraction angle range

(20) from $20^{\circ}$ to $60^{\circ}$. The make and model of SIMS was CAMECA IMS-7f with $\mathrm{O}^{2+}$ ion source and image resolution $\fallingdotseq 10,000$, mass range $\fallingdotseq 300$. The SIMS instrument was used by an internally yielded beam ions focused on a sample surface to produce secondary ions. The generated ions were then passed through a mass spectrometer across a high electrostatic potential. The depth profiles of elemental and molecular species could be assessed by SIMS analysis. The AFM model and make are Bruker Dimension Icon. The image resolution of $X-Y$ noise was less than $0.15 \mathrm{~nm}$ and $Z$ noise less than $30 \mathrm{pm}$ (Close Loop). The scanning range $(X, Y)$ was $1 \mu \mathrm{m} * 1 \mu \mathrm{m}$. The AFM in Bruker Dimension Icon modes with intermittent contact was using a silicon tip with a $10 \mathrm{pN} / \mathrm{nm}$ spring constant. A sample area of $3 \times 3 \mu \mathrm{m}$ was scanned with actuation rates up to $8 \mathrm{kHz}$ in air and fluid.

The XPS model and make are XPS ULVAC-PHI and PHI 5000. The XPS spectra were carried out by a VG ESCA Scientific Theta Probe. As for the XPS instrument condition, the X-ray spot size was about $15 \mu \mathrm{m}$, the take-off angle was around $53^{\circ}$ and the pass energy was set as $50 \mathrm{eV}$. The X-ray source for the XPS measurement was $\mathrm{Al} \mathrm{K \alpha}(1486.6 \mathrm{eV})$. Furthermore, the sputtering argon ion beam with a beam energy of $3 \mathrm{kV}$ was operated at a current density of $1 \mu \mathrm{A} / \mathrm{mm}^{2}$.

\section{Results and Discussion}

In this study, the as-deposited InGaZnO samples were subjected to the $\mathrm{NH}_{3}$ plasma treatment, material characterizations and sensing measurements were performed on the as-deposited samples and the samples with $\mathrm{NH}_{3}$ plasma treatment. To examine the surface morphologies both on the surface and through the cross section, SEM images on the surface and TEM images on the cross section of the InGaZnO sample were taken. The InGaZnO sample with $\mathrm{NH}_{3}$ plasma treatment and the $\mathrm{Mg}$-doped InGaZnO sample with plasma treatment are shown in Figures 2 and 3. Both AFM and SEM images revealed that some crystals were generated on the surface of the samples treated with $\mathrm{NH}_{3}$ plasma compared with the untreated $\mathrm{InGaZnO}$ samples. Moreover, line-shaped stripes in the untreated InGaZnO sample were reduced by $\mathrm{NH}_{3}$ plasma treatment, and even eliminated by $\mathrm{Mg}$ doping plus $\mathrm{NH}_{3}$ plasma treatment [3], as shown in Figures 2 and 3. Based on previous studies, $\mathrm{NH}_{3}$ plasma treatment can roughen the surface and hence enhance the crystallization and grain size [11]. Therefore, the sensing factor $\beta$ could be increased with the increased roughness value as shown on the AFM images (Figure 3) because the number of sites exposed to the solution was enlarged. Moreover, the $\mathrm{N}$ atoms caused by $\mathrm{NH}_{3}$ plasma incorporated into the film could mitigate the dangling bonds and reduce the traps [13]. 

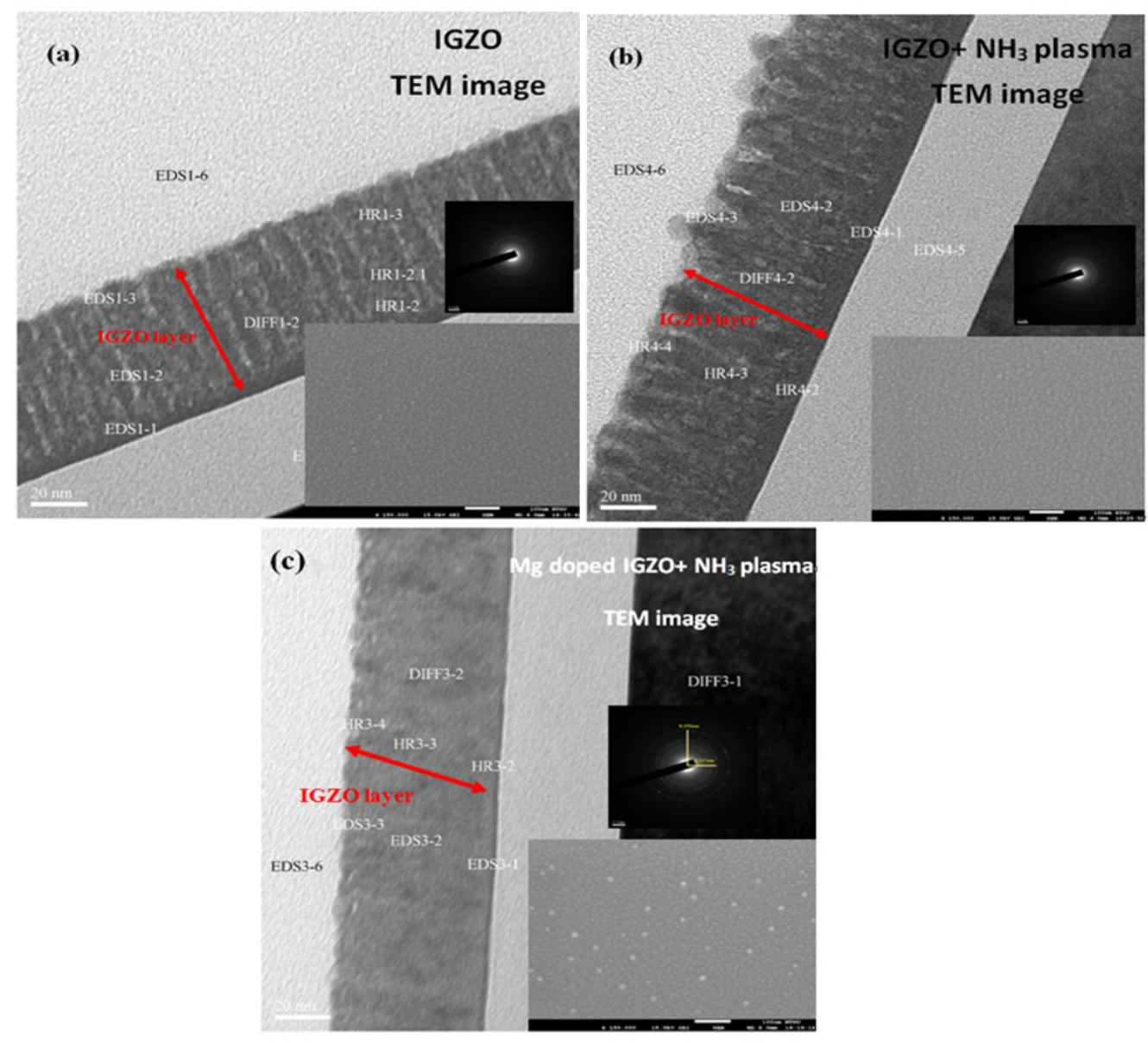

Figure 2. TEM images with SAED, FESEM sub-images for (a) IGZO sample (b) IGZO with $\mathrm{NH}_{3}$ plasma treatment (c) Mg doped IGZO with $\mathrm{NH}_{3}$ plasma treatment.
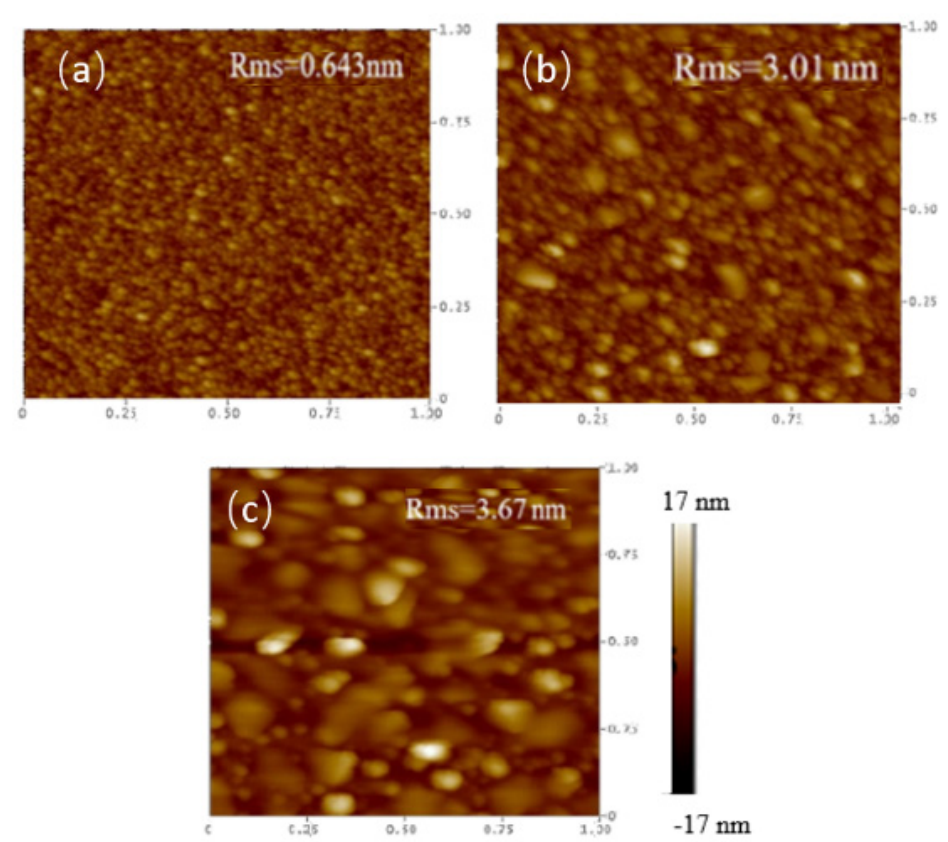

Figure 3. AFM images for (a) IGZO sample (b) IGZO with $\mathrm{NH}_{3}$ plasma treatment (c) $\mathrm{Mg}$ doped IGZO with $\mathrm{NH}_{3}$ plasma treatment. 
Furthermore, the photoluminescence (PL) peak was enhanced and blue-shifted, which may result from crystallization. In addition, contact angle measurements revealed that the enhancement of hydrophilic properties might result from modification of the surface due to $\mathrm{Mg}$ doping, as shown in Figure 4.

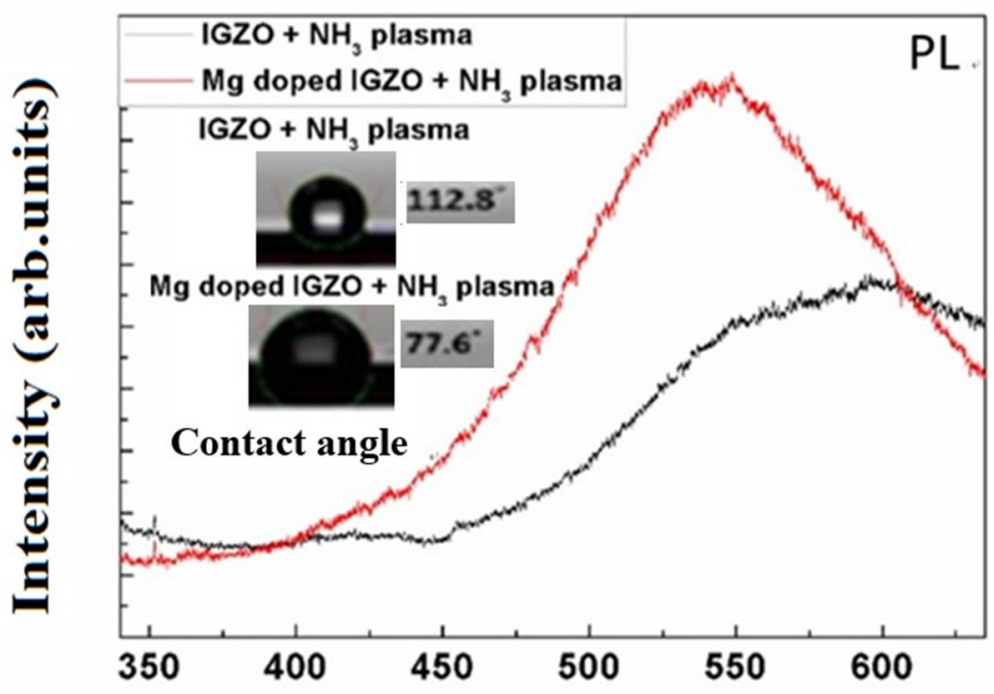

Figure 4. PL spectra and surface contact angle measurements for IGZO with $\mathrm{NH}_{3}$ plasma treatment and $\mathrm{Mg}$ doped IGZO with $\mathrm{NH}_{3}$ plasma treatment.

In addition to studying morphologies, XRD, XPS, and SIMS were used to investigate the crystalline phases, chemical bindings, and incorporated atoms versus depth, respectively [4]. Figure 5a,b show XRD patterns for the undoped InGaZnO and Mg-doped InGaZnO membranes with various $\mathrm{NH}_{3}$ plasma treatments, showing that Mg-doping and plasma treatment could enhance the crystalline phase. The strongest crystallization occurred in the 3-min plasma treatment of the Mg-doped samples. As the plasma treatment time increased to $6 \mathrm{~min}$, the crystalline phase became weaker. In addition, $\mathrm{Mg}$ co-sputtering can form magnesium oxide (MgO) crystals into IGZO as shown in Figure $5 \mathrm{a}, \mathrm{b}$ and therefore, the sensing behavior can be improved [30,31]. The electronegativity of $\mathrm{Mg}(\chi=1.31)$ is low and stablize the binding with oxygen [32]. Moreover, magnesium atoms can replace the vacancies and repair dangling bonds to passivate defects in oxides [33]. Therefore. the membrane films with better material quality can have better $\mathrm{pH}$ sensing capability.

XPS spectra for the undoped and Mg-doped samples shown in Figure $5 \mathrm{c}$, d show that an $\mathrm{N}$-chemical binding peak emerged with the $\mathrm{NH}_{3}$ plasma treatment. Moreover, the strongest $\mathrm{N}$-binding occurred at $3 \mathrm{~min}$ of plasma treatment for both the undoped and Mg-doped samples. This analysis is in line with the XRD patterns. Furthermore, SIMS data revealed that the incorporation $\mathrm{N}$ and $\mathrm{Mg}$ atoms along the depth of the undoped and Mg-doped samples, as shown in Figure 5e,f. Results indicate that $\mathrm{N}$ atoms could be uniformly distributed along the depth of the membrane to passivate defects, as shown in Figure 5e,f. Moreover, high concentrations of $\mathrm{Mg}$ could be found in the Mg-doped membrane. SIMS analysis of the showed that In, Ga, and Zn distribution spiked near the membrane/Si interface were mitigated and the defects were suppressed in the doped samples, likely due to $\mathrm{Mg}$ doping. This suppression may mitigate defects near the interface, and hence further boost sensing behaviors for the Mg-doped membrane [5]. 


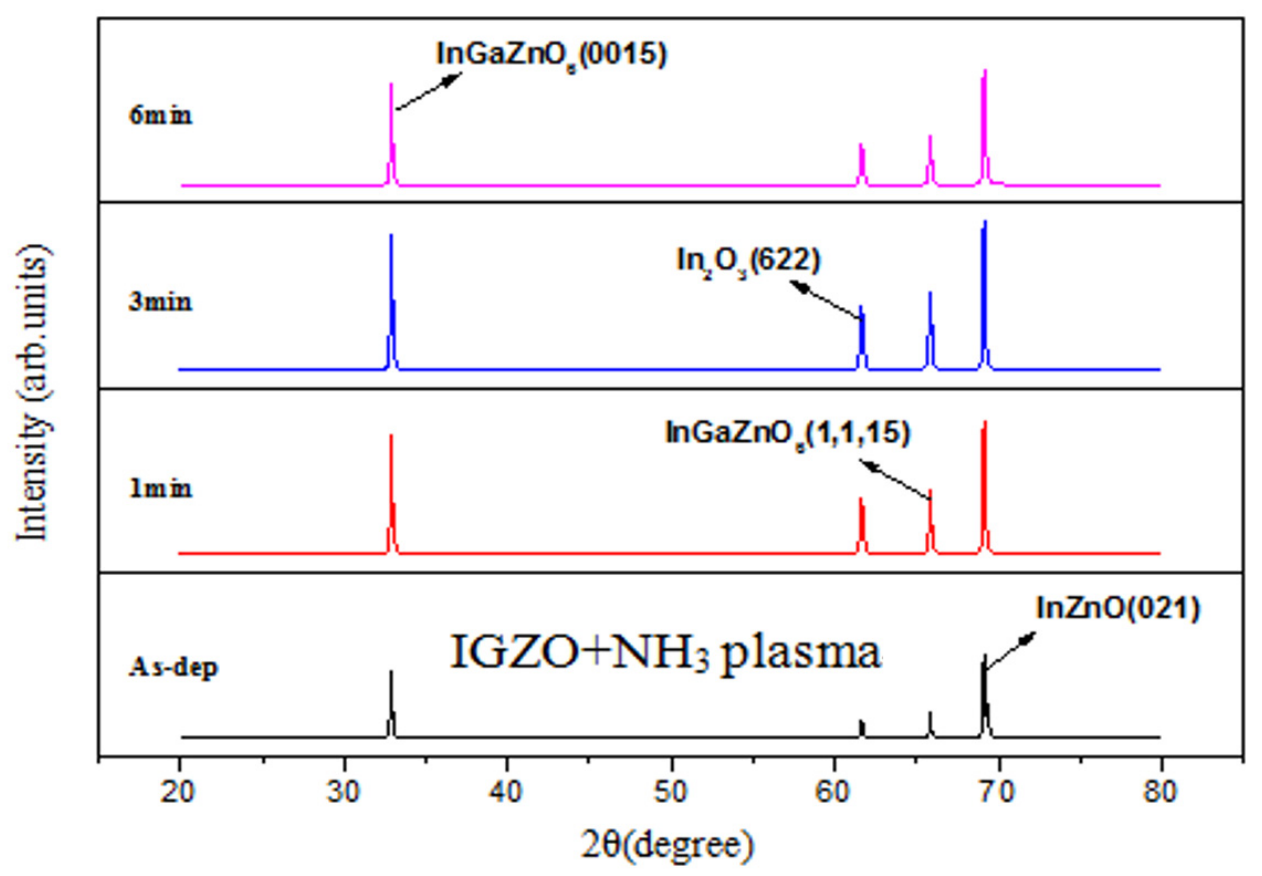

(a)

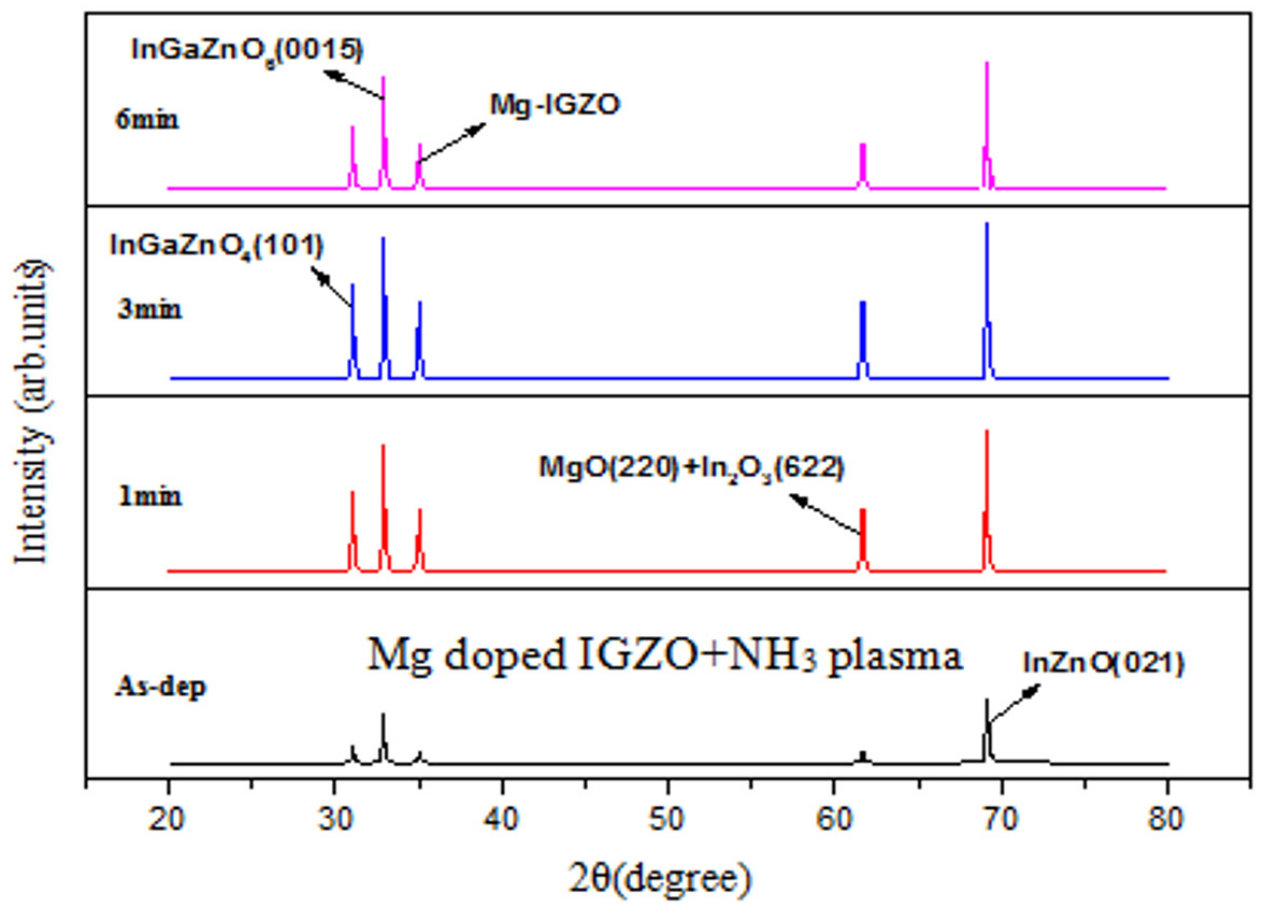

(b)

Figure 5. Cont. 


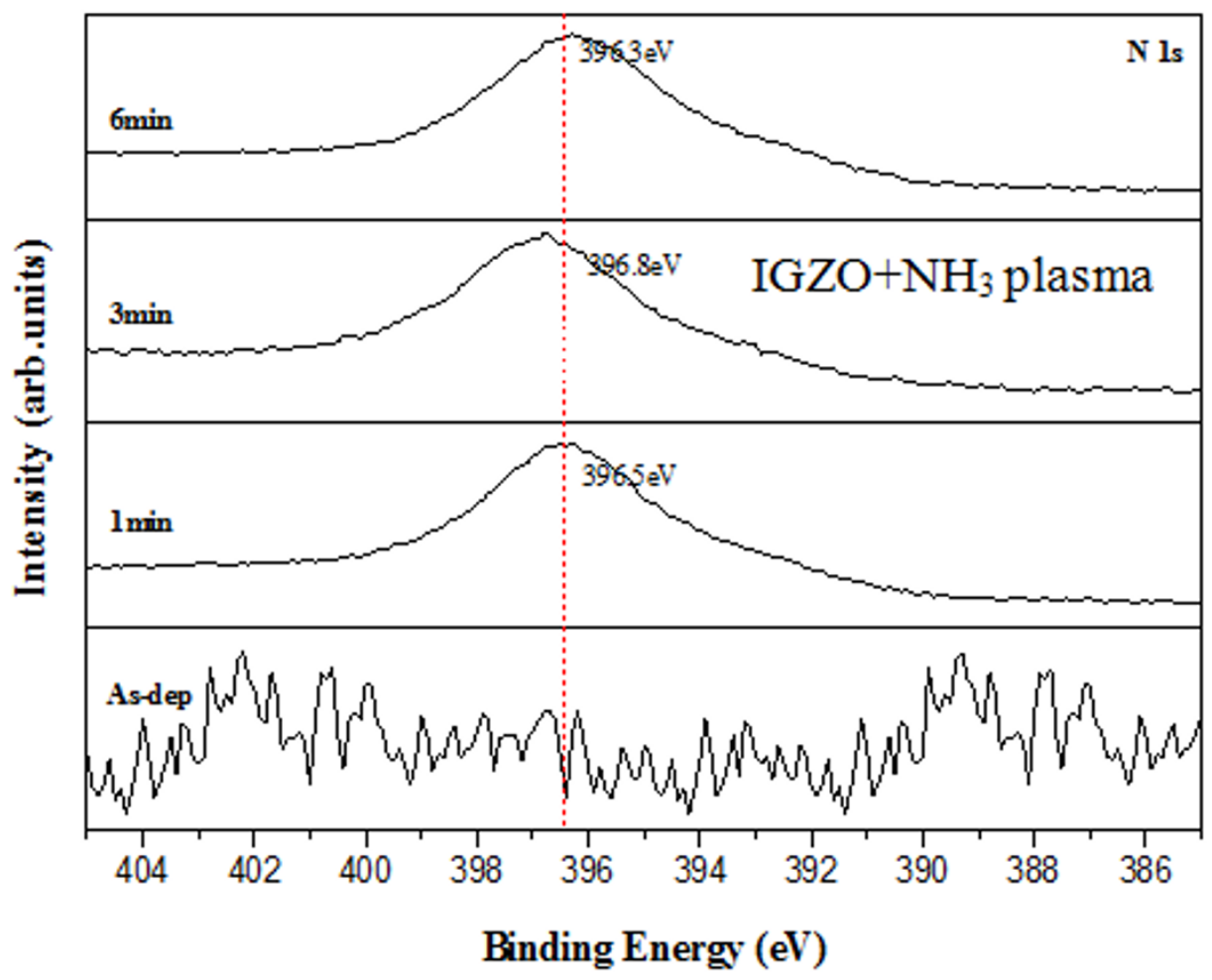

(c)

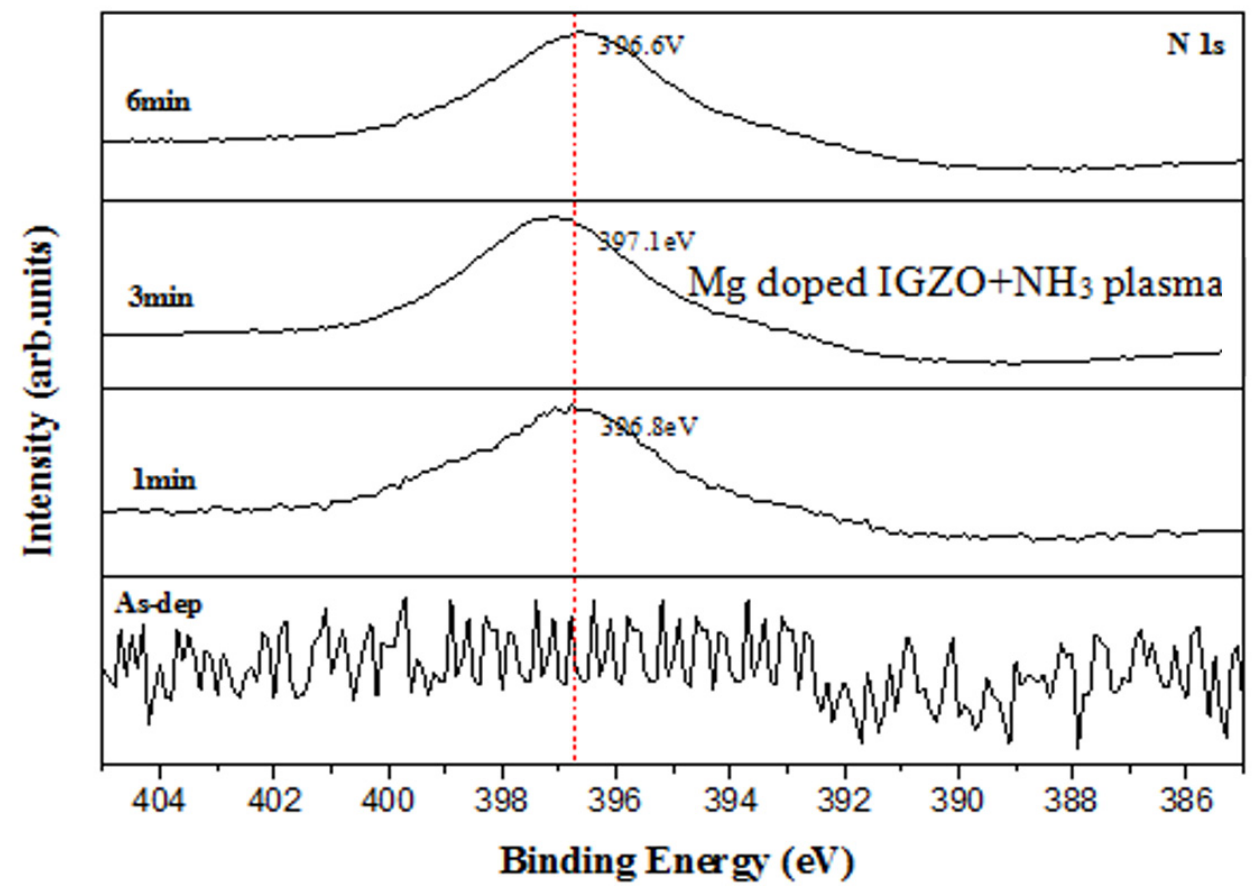

(d)

Figure 5. Cont. 


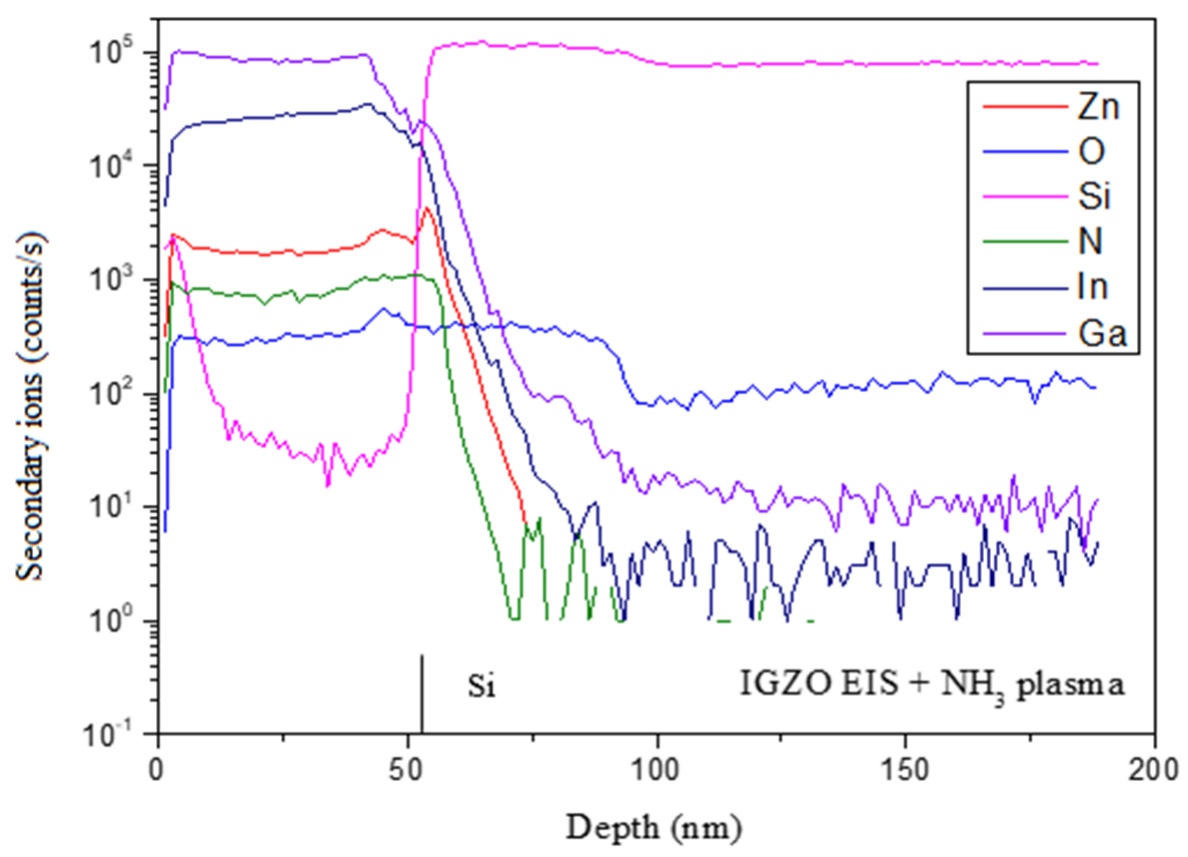

(e)

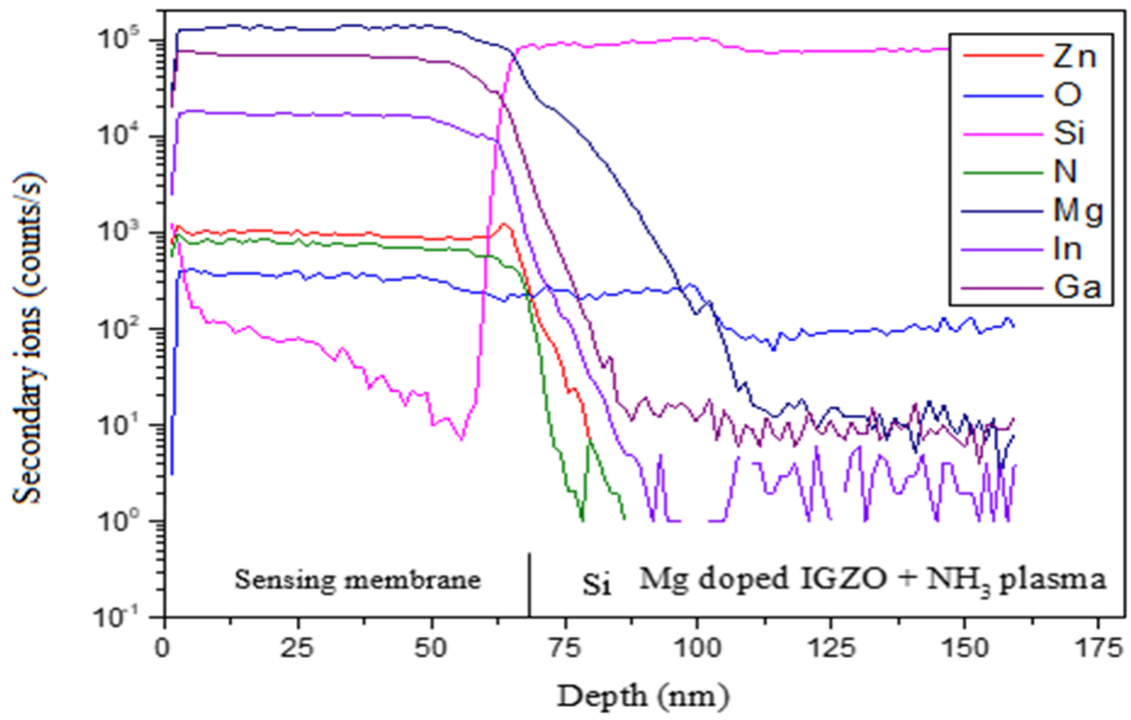

(f)

Figure 5. XRD patterns for (a) IGZO with $\mathrm{NH}_{3}$ plasma treatment and (b) $\mathrm{Mg}$ doped IGZO with $\mathrm{NH}_{3}$ plasma treatment. $\mathrm{N}$ 1s XPS spectra for (c) IGZO with $\mathrm{NH}_{3}$ plasma treatment (only noise for the as-deposited sample: not shown) and (d) $\mathrm{Mg}$ doped IGZO with $\mathrm{NH}_{3}$ plasma treatment. (Various plasma treatment times are included in $(\mathbf{a}-\mathbf{c})$, (only noise for the as-deposited sample: not shown) and (d). SIMS data for (e) IGZO with $\mathrm{NH}_{3}$ plasma treatment for $3 \mathrm{~min}$ and (f) $\mathrm{Mg}$ doped IGZO with $\mathrm{NH}_{3}$ plasma treatment for $3 \mathrm{~min}$.

After morphological and material characterizations, sensing behaviors of the undoped and Mg-doped membranes with NH3 plasma treatment were evaluated [17]. To evaluate the $\mathrm{pH}$ sensing behavior of a sensing membrance $\mathrm{C}-\mathrm{V}$ curves were taken. The capacitance changed with gate bias voltage swept for $3 \mathrm{~V}$ interval. As a reference capacitance of $0.4 \mathrm{Cmax}$ is set, the values of reference voltages versus pHvaues could be extracted from 
the $\mathrm{C}-\mathrm{V}$ curves. The $\mathrm{pH}$ sensitivity and linearity could be calculated from the subfigure of reference voltages versus $\mathrm{pH}$ values. The $\mathrm{pH}$ senesing evaluated from $\mathrm{C}-\mathrm{V}$ curves.

Figure $6 \mathrm{a}, \mathrm{b}$ show the sensing capability measurements for the undoped and $\mathrm{Mg}$-doped membranes with $\mathrm{NH}_{3}$ plasma treatment for $3 \mathrm{~min}$. Results indicate that the $\mathrm{pH}$ sensing sensitivity for the undoped InGaZnO membrane achieved $62.28 \mathrm{mV} / \mathrm{pH}$, which was above Nernst limit. However, the sensitivity of the Mg-doped membrane was as high as $65.85 \mathrm{mV} / \mathrm{pH}$, indicating that both $\mathrm{Mg}$ doping and $\mathrm{NH}_{3}$ plasma treatment could effectively enhance crystallization, reduce defects in the bulk and interface, and reinforce membrane material quality. As shown in Table 1 , the sensitivity of $\mathrm{NH}_{3}$ plasma treated $\mathrm{InGaZnO}$ sample and $\mathrm{Mg}$ doped $\mathrm{InGaZnO}$ sample have $\mathrm{pH}$ sensitivity of 62.28 and $65.85 \mathrm{mV} / \mathrm{pH}$, which are above Nernst limit (around $60 \mathrm{mV} / \mathrm{pH}$ ), while the $\mathrm{InGaZnO}$ and Mg-doped InGaZnO sample with appropriate annealing at $500{ }^{\circ} \mathrm{C}$ have the $\mathrm{pH}$ sensitivity of 56.51 and $59.3 \mathrm{mV} / \mathrm{pH}$, which are below Nernst limit. Compared with plasma treatment with other gases, $\mathrm{NH}_{3}$ might be more effective. Since nitrogen $(\mathrm{N})$ was similar to oxygen $(\mathrm{O})$ in regard to ionic radius and acts as a better compensator, $\mathrm{NH}_{3}$ plasma was used in the post-treatment of sputter film. Therefore, we investigated the impact of $\mathrm{NH}_{3}$ plasma treatment on the sensing behavior, surface morphology, and crystal structure. Due to the $\mathrm{NH}_{3}$ plasma treatment, plasma-induced morphological changes and increment of grain size were observed, favoring the increase of surface roughness and number of surface defect sites, and thus resulting in higher sensitivity and linearity. The surface charge density was mainly related to the ionic activity in the solution.

Table 1. Comparison of InGaZnO and $\mathrm{Mg}$ doped $\mathrm{InGaZnO}$ samples with annealing at $500{ }^{\circ} \mathrm{C}$ and $\mathrm{NH}_{3}$ plasma treatment for $3 \mathrm{~min}$.

\begin{tabular}{|c|c|c|}
\hline Sample & Sensitivity & Linearity \\
\hline IGZO w/o annealing & $39.08 \mathrm{mV} / \mathrm{pH}$ & $95.37 \%$ \\
\hline $\mathrm{Mg}$-doped IGZO annealed at $500^{\circ} \mathrm{C}$ & $56.51 \mathrm{mV} / \mathrm{pH}$ & $98.79 \%$ \\
\hline Mg-doped IGZO w/o annealing & $43.45 \mathrm{mV} / \mathrm{pH}$ & $99.234 \%$ \\
\hline $\mathrm{Mg}$-doped IGZO annealed at $600^{\circ} \mathrm{C}$ & $59.3 \mathrm{mV} / \mathrm{pH}$ & $99.128 \%$ \\
\hline $\mathrm{IGZO} \mathrm{NH}_{3}$ plasma 3 min & $62.28 \mathrm{mV} / \mathrm{pH}$ & $99.45 \%$ \\
\hline Mg-doped IGZO $\mathrm{NH}_{3}$ plasma $3 \mathrm{~min}$ & $65.85 \mathrm{mV} / \mathrm{pH}$ & $99.03 \%$ \\
\hline
\end{tabular}

To assess the stability of the tested membranes, the hysteresis voltages and the drift effect were evaluated. To investigtate the hysteresis effects, the membranes were immersed in solutions with various $\mathrm{pH}$ values of $7,4,10$, and 7 in an alternate time sequence. The submerging time was five minutes in each solution. The hysteresis voltage could be calculated by the voltage deviation between the initial and the terminal voltages taken in the $\mathrm{pH}$ loop. The dangling bonds could bind with the ions in the solutions, hysteresis response could be observed.

Hysteresis voltage measurements were then taken for the undoped and Mg-doped membranes, shown in Figure $6 \mathrm{c}, \mathrm{d}$, respectively, show that $\mathrm{NH}_{3}$ plasma treatment with a time of 3 min can effectively suppress hysteresis voltage, possibly from the removal of the dangling bonds and traps [34]. Compared with the as-deposited InGaZnO film and the as-deposited $\mathrm{Mg}$ doped film, the $\mathrm{NH}_{3}$ plasma treatment could lower the hysteresis voltage from 18.42 to $1.68 \mathrm{eV}$ for the undoped sample and from 16.62 to $1.01 \mathrm{eV}$ for the Mg-doped sample, respectively. 


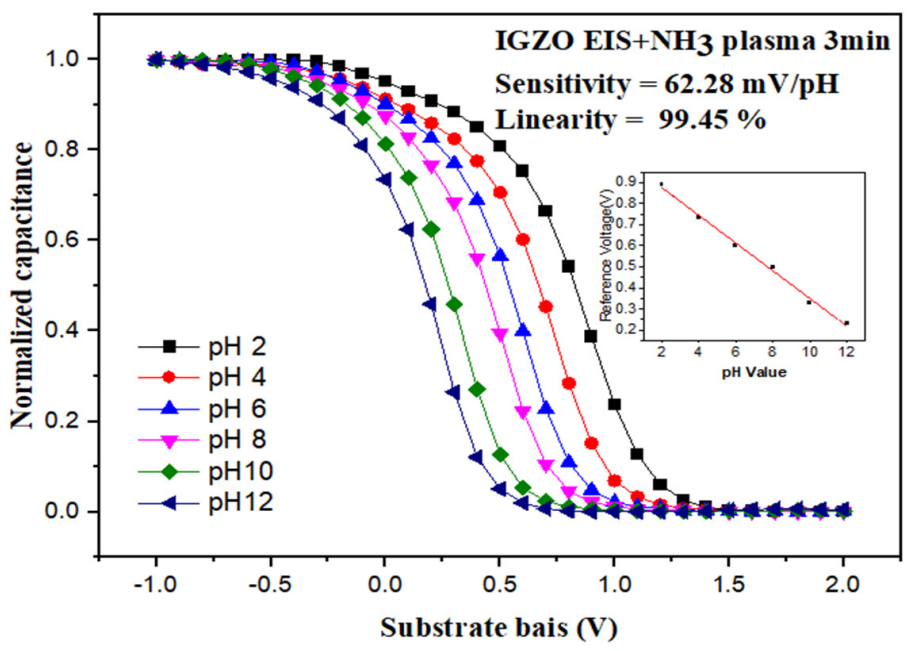

(a)

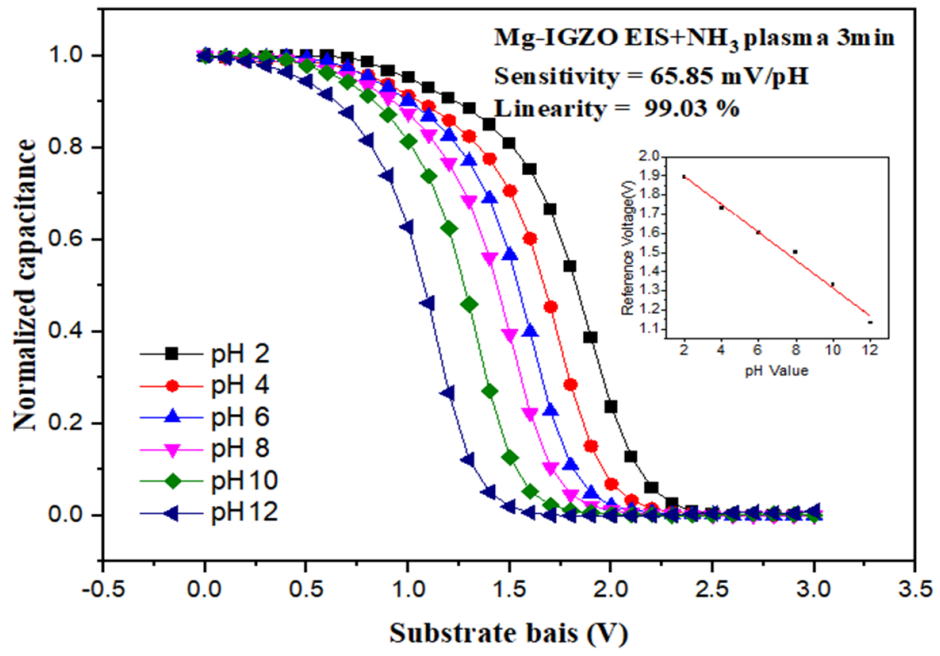

(b)

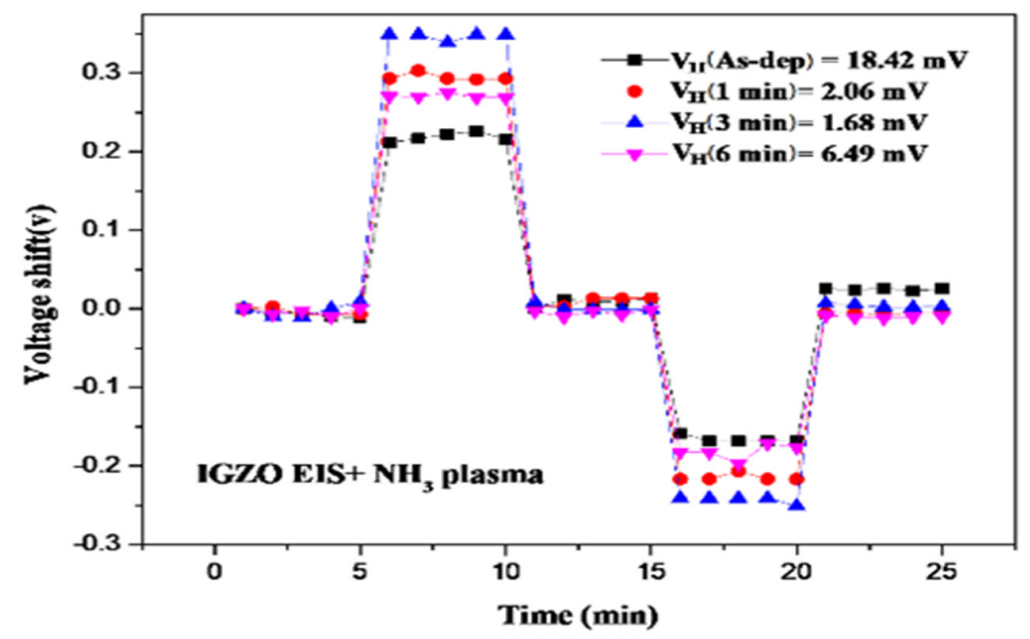

(c)

Figure 6. Cont. 


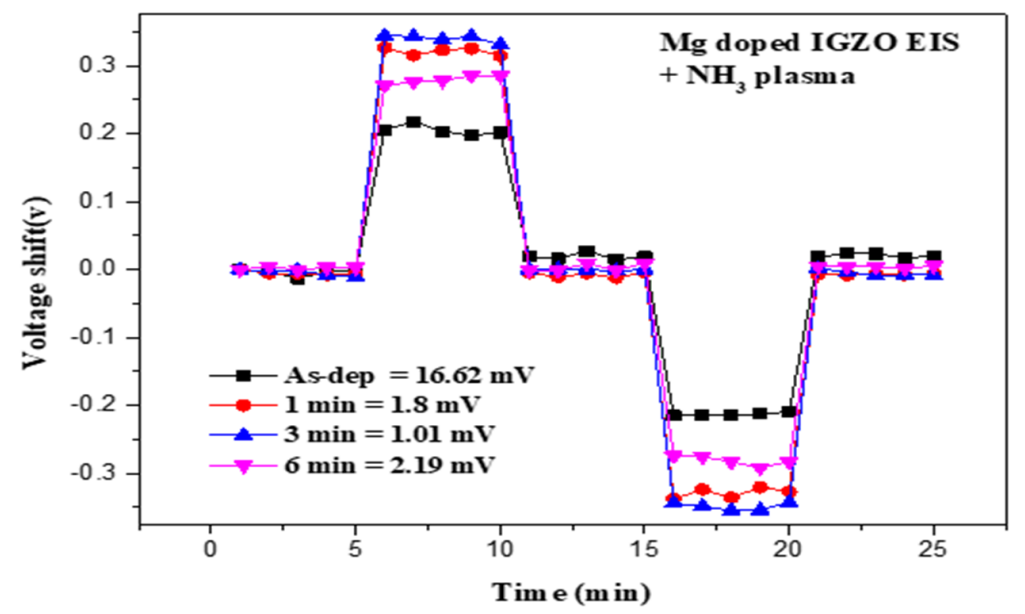

(d)

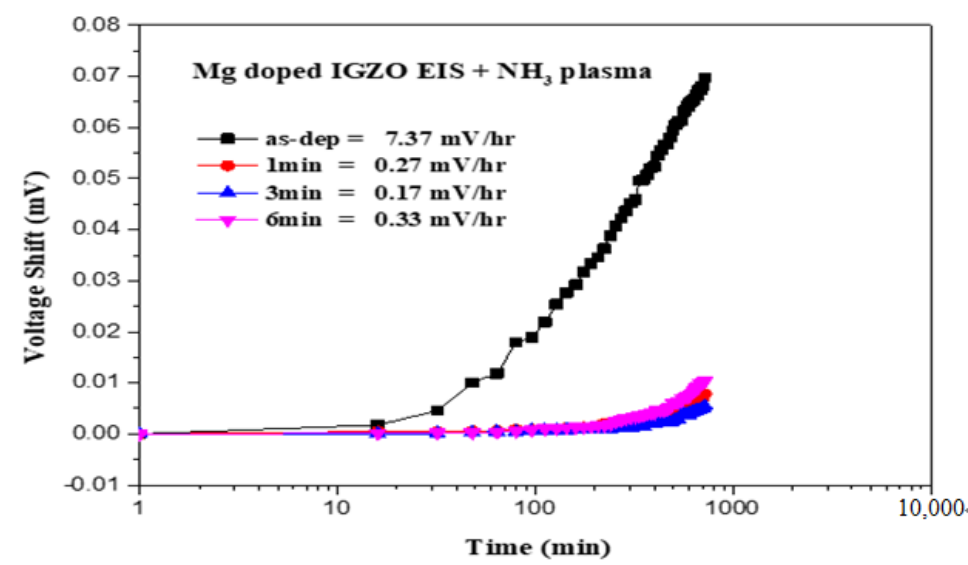

(e)

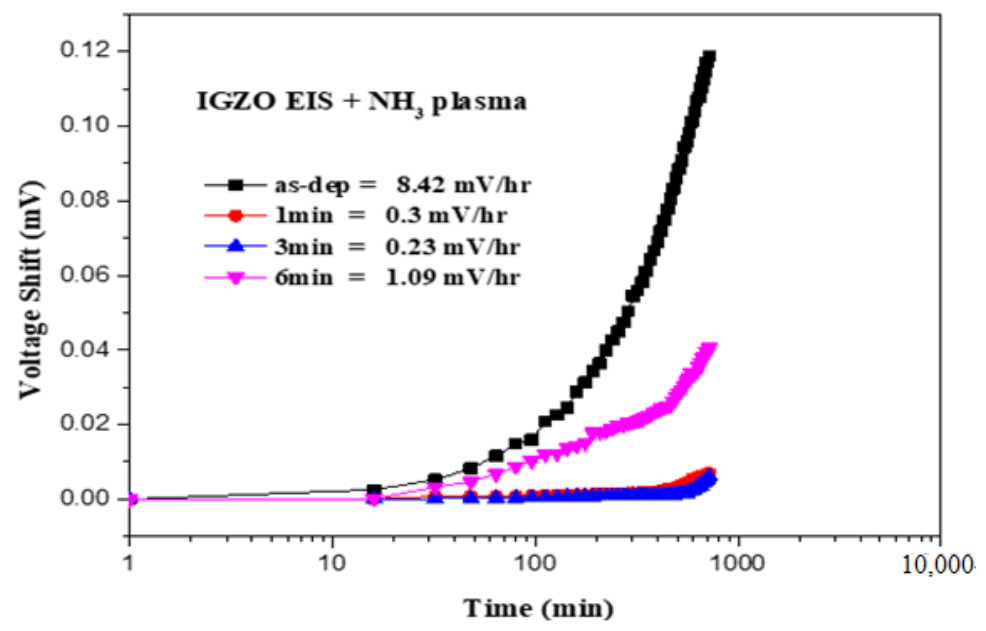

(f)

Figure 6. The $\mathrm{C}-\mathrm{V}$ curves and the extracted $\mathrm{pH}$ sensitivity and linearity of the sensing data of (a) IGZO with $\mathrm{NH}_{3}$ plasma treatment for 3 min and (b) Mg doped IGZO with $\mathrm{NH}_{3}$ plasma treatment for $3 \mathrm{~min}$. The hysteresis voltage measurements for (c) IGZO with $\mathrm{NH}_{3}$ plasma treatment for 3 min and (d) $\mathrm{Mg}$ doped IGZO with $\mathrm{NH}_{3}$ plasma treatment for $3 \mathrm{~min}$. The drift voltage measurements for (e) IGZO with NH3 plasma treatment for 3 min and (f) $\mathrm{Mg}$ doped IGZO with $\mathrm{NH}_{3}$ plasma treatment for $3 \mathrm{~min}$. 
Finally To examine the drift rate voltage for long-time reliability, the samples were submerged in a pH7 buffer solution for $12 \mathrm{~h}$. Consistent with the material and sensing characterizations, drift voltage rate measurements for the undoped and Mg-doped samples revealed that $\mathrm{NH}_{3}$ plasma treatment could effectively remove the defective bindings as shown in Figure 6e,f. Plasma treatment could potentially cause the membrane to bind with ions in the solution. Moreover, $\mathrm{Mg}$ doping could further lower both the hysteresis voltage and drift rate, since incorporated $\mathrm{Mg}$ atoms might fill in the vacancies and bind with dangling bonds to enhance material quality. The drift voltage shift could also be induced by the ions captured by the dangling bonds, too. To illustrate the voltge shifts in the hysteresis and drift voltage measurements, Figure 7 explain the mechansim for hysteresis and drift voltage shifts caused by dangling bonds. In the beginning, no ions were attached on the dangling bonds. As the measuring time passed by, more and more ions were captured by the dangling bonds and the gate voltage shifts might occur as shown in Figure 7.

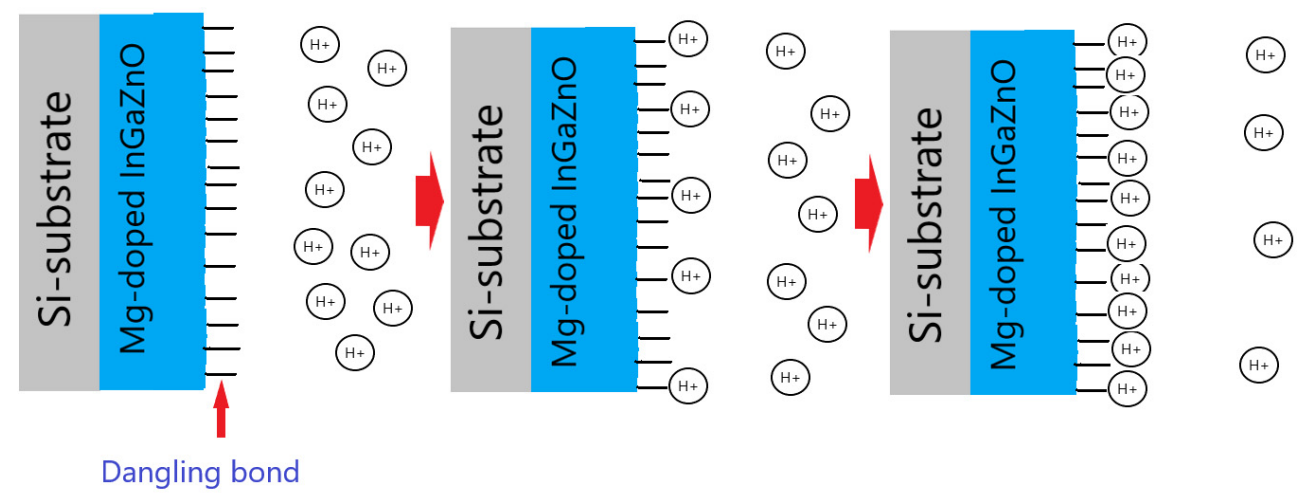

Figure 7. The mechansim for hysteresis and drift voltage shifts caused by dangling bonds.

Based on previous reports [23,35-37], Mg doping can generate $\mathrm{Mg}^{2+}$ near the surface of the membrane and attract some $\mathrm{OH}^{-}$ions in the electrolyte solution. Therefore, the $\mathrm{OH}^{-}$in the diffusion layer of the electrolyte solution might decrease, and therefore the $\mathrm{C}_{\mathrm{DL}}$ (diffusion capacitance) might decrease as well. The illustration of $\mathrm{C}_{\mathrm{DL}}$ decrease is shown in Figure 8 . Then, the membrane parameter $\beta$, the surface potential, and overall sensitivity could also be boosted. However, though $\mathrm{NH}_{3}$ plasma treatment could incorporate $\mathrm{N}$ atoms into the membrane and potentially decrease defects, it could not cause $\mathrm{Mg}$ atoms in the membrane to be uniformly distributed in the same way that Rapid Thermal Anneaing (RTA) annealing did in our previous research. Therefore, linearity could be decreased due to the uneven distribution of $\mathrm{Mg}$ atoms with the plasma treatment. In the future, a combination of RTA annealing and $\mathrm{NH}_{3}$ plasma treatment could be conducted to further improve the sensitivity and linearity of the membrane. As the plasma treatment time increased to $6 \mathrm{~min}$, the hysteresis voltage and drift rate increased drastically. Since plasma treatment could damage the film by etching away the surface, plasma treatment with a time longer than $6 \mathrm{~min}$ could deteriorate the surface material quality consistent with the XRD analysis as shown in Figure 5. Therefore, plasma treatment with an appropriate time could optimize the material properties and device performance. 


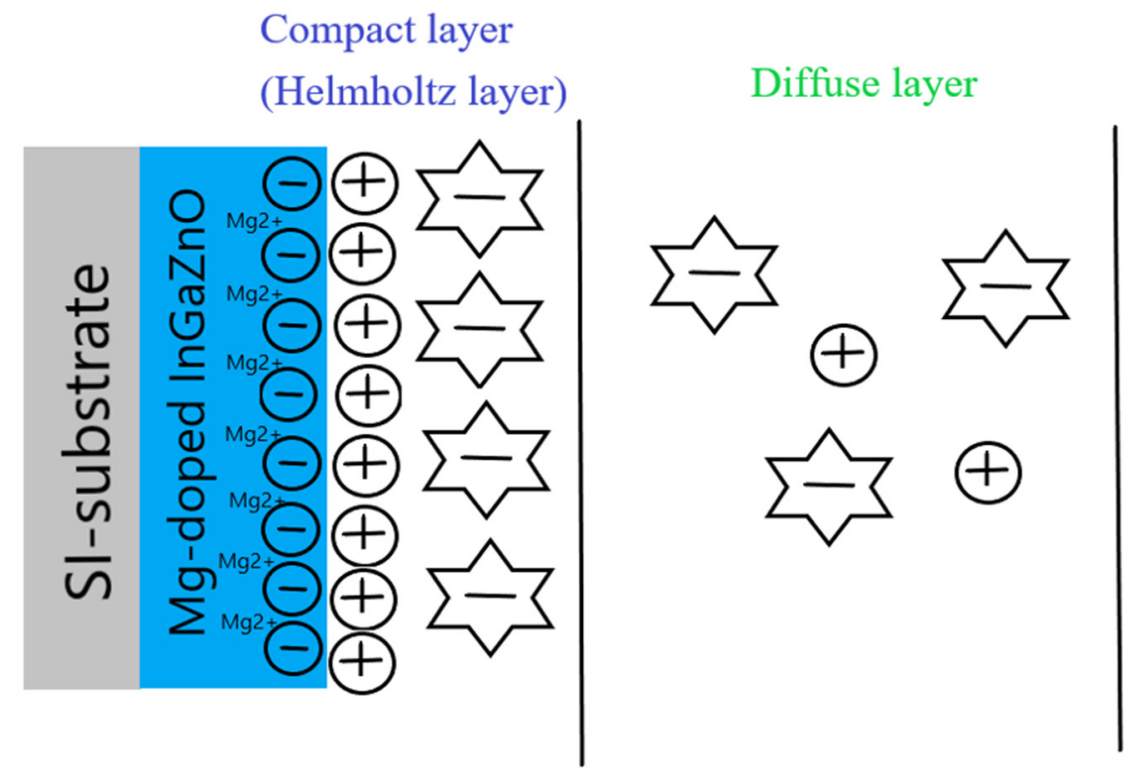

Figure 8. The $\mathrm{C}_{\mathrm{DL}}$ decrease caused by $\mathrm{Mg}$ doping in the site-binding model.

\section{Conclusions}

In this study, $\mathrm{Mg}$ doping and $\mathrm{NH}_{3}$ plasma treatment were incorporated into the fabrication process of InGaZnO membranes. Inclusion of $\mathrm{Mg}$ and $\mathrm{N}$ atoms into the membrane could enhance crystallization, strengthen chemical binding, and reduce defects, as revealed in morphological and material characterizations. Evaluation of the sensing behavior also indicated that $\mathrm{Mg}$ doping and $\mathrm{NH}_{3}$ plasma treatment with a time of 3 min could boost the sensing behaviors above the Nernst limit, and also enhance low hysteresis voltage and drift rate. Our results indicate that $\mathrm{Mg}$-doped $\mathrm{InGaZnO}$ membranes with $\mathrm{NH}_{3}$ plasma treatment show promise for future industrial $\mathrm{pH}$ sensing EIS-based biosensors.

Author Contributions: Conceptualization, C.-H.K. and H.C.; methodology, C.-H.K., C.-S.L. and H.C.; data curation, C.-S.L.; writing-original draft preparation, S.-M.C., C.-C.K., S.-C.T. and H.C.; writingreview and editing, H.C.; visualization, H.C.; supervision, C.-H.K. and H.C.; project administration, H.C.; funding acquisition, M.-L.L. and H.C. All authors have read and agreed to the published version of the manuscript.

Funding: This research was funded by Ministry of Science and Technology (MOST), Taiwan, grant number "110-2221-E-260-006" and "110-2222-E-159-002-MY2".The APC was funded by Minghsin University of Science and Technology".

Institutional Review Board Statement: Not applicable.

Informed Consent Statement: Not applicable.

Data Availability Statement: The data used to support the findings of this study are available from the corresponding author upon request.

Acknowledgments: This work was financially supported by the "Center for the Semiconductor Technology Research" from The Featured Areas Research Center Program within the framework of the Higher Education Sprout Project by the Ministry of Education (MOE) in Taiwan. Also supported in part by the Ministry of Science and Technology, Taiwan, under Grant MOST 110-2634-F-009-027, 110-2222-E-159-002-MY2 and MOST 110-2221-E-260-006.

Conflicts of Interest: There is no conflict of interest to declare. The funders had no role in the design of the study; in the collection, analyses, or interpretation of data; in the writing of the manuscript, or in the decision to publish the result. 


\section{References}

1. Bie, Y.Q.; Liao, Z.M.; Zhang, H.Z.; Li, G.R.; Ye, Y.; Zhou, Y.B.; Xu, J.; Qin, Z.X.; Dai, L.; Yu, D.P. Self-Powered, Ultrafast, VisibleBlind UV Detection and Optical Logical Operation based on ZnO/GaN Nanoscale p-n Junctions. Adv. Mater. 2011, $23,649-653$. [CrossRef] [PubMed]

2. Chang, C.-J.; Lin, Y.-G.; Weng, H.-T.; Wei, Y.-H. Photocatalytic hydrogen production from glycerol solution at room temperature by ZnO-ZnS/graphene photocatalysts. Appl. Surf. Sci. 2018, 451, 198-206. [CrossRef]

3. Tsay, C.-Y.; Wu, P.-H. Properties of solution-processed MgInZnO semiconductor thin films and photodetectors fabricated at a low temperature using UV-assisted thermal annealing. Ceram. Int. 2017, 43, 11874-11878. [CrossRef]

4. Tsay, C.-Y.; Wu, P.-H. Incorporation of sol-gel-derived $\mathrm{Mg}$ into InZnO semiconductor thin films for metal-semiconductor-metal ultraviolet photodetectors. Jpn. J. Appl. Phys. 2017, 56, 03BA02. [CrossRef]

5. Wang, I.-S.; Lin, Y.-T.; Huang, C.-H.; Lu, T.-F.; Lue, C.-E.; Yang, P.; Pijanswska, D.G.; Yang, C.-M.; Wang, J.-C.; Yu, J.-S.; et al. Immobilization of enzyme and antibody on ALD-HfO2-EIS structure by NH3 plasma treatment. Nanoscale Res. Lett. 2012, 7, 179. [CrossRef]

6. Chou, J.-C.; Chen, J.-S.; Huang, M.-S.; Liao, Y.-H.; Lai, C.-H.; Wu, T.-Y.; Yan, S.-J. The Characteristic Analysis of IGZO/Al pH Sensor and Glucose Biosensor in Static and Dynamic Measurements. IEEE Sens. J. 2016, 16, 8509-8516. [CrossRef]

7. Lin, C.F.; Kao, C.H.; Lin, C.Y.; Liu, Y.W.; Wang, C.H. The electrical and physical characteristics of Mg-doped ZnO sensing membrane in EIS (electrolyte-insulator-semiconductor) for glucose sensing applications. Results Phys. 2020, 16, 102976. [CrossRef]

8. Kumar, P.; Maikap, S.; Singh, K.; Chatterjee, S.; Chen, Y.-Y.; Cheng, H.-M.; Mahapatra, R.; Qiu, J.-T.; Yang, J.-R. Highly Reliable Label-Free Detection of Urea/Glucose and Sensing Mechanism Using $\mathrm{SiO}_{2}$ and CdSe-ZnS Nanoparticles in Electrolyte-InsulatorSemiconductor Structure. J. Electrochem. Soc. 2016, 163, B580-B587. [CrossRef]

9. Kumar, P.; Maikap, S.; Qiu, J.T.; Jana, S.; Roy, A.; Singh, K.; Cheng, H.M.; Chang, M.T.; Mahapatra, R.; Chiu, H.C.; et al. Detection of $\mathrm{pH}$ and Enzyme-Free $\mathrm{H}_{2} \mathrm{O}_{2}$ Sensing Mechanism by Using $\mathrm{GdO}$ x Membrane in Electrolyte-Insulator-Semiconductor Structure. Nanoscale Res. Lett. 2016, 11, 434. [CrossRef] [PubMed]

10. Kao, C.H.; Chang, C.L.; Su, W.M.; Chen, Y.T.; Lu, C.C.; Lee, Y.S.; Hong, C.H.; Lin, C.Y.; Chen, H. Magnesium Oxide (MgO) $\mathrm{pH}$-sensitive Sensing Membrane in Electrolyte-Insulator-Semiconductor Structures with $\mathrm{CF}_{4}$ Plasma Treatment. Sci. Rep. 2017, 7, 7185. [CrossRef] [PubMed]

11. Hu, S.; Li, F.; Fan, Z.; Gui, J. Improved photocatalytic hydrogen production property over $\mathrm{Ni} / \mathrm{NiO} / \mathrm{N}-\mathrm{TiO} 2-\mathrm{x}$ heterojunction nanocomposite prepared by $\mathrm{NH}_{3}$ plasma treatment. J. Power Sources 2014, 250, 30-39. [CrossRef]

12. Kang, D.H.; Kang, I.; Ryu, S.H.; Jang, J. Self-Aligned Coplanar a-IGZO TFTs and Application to High-Speed Circuits. IEEE Electron Device Lett. 2011, 32, 1385-1387. [CrossRef]

13. Lai, C.; Lue, C.; Yang, C.; Jao, J.; Tai, C. New pH-sensitive TaOxNy membranes prepared by $\mathrm{NH}_{3}$ plasma surface treatment and nitrogen incorporated reactive sputtering. Sens. Actuators B Chem. 2018, 130, 77-81. [CrossRef]

14. Kao, C.H.; Chang, C.W.; Chen, Y.T.; Su, W.M.; Lu, C.C.; Lin, C.Y.; Chen, H. Influence of $\mathrm{NH}_{3}$ plasma and Ti doping on pH-sensitive $\mathrm{CeO}_{2}$ electrolyte-insulator-semiconductor biosensors. Sci. Rep. 2017, 7, 2405. [CrossRef]

15. Kim, J.; Kim, T.H.; Oh, S.; Nam, J.H.; Jang, H.Y.; Kim, Y.; Yamada, N.; Kobayashi, H.; Kim, S.-Y.; Lee, B.H.; et al. Al $\mathrm{Al}_{3}$-Induced Sub-Gap Doping on the IGZO Channel for the Detection of Infrared Light. ACS Appl. Electron. Mater. 2020, 2, 1478-1483. [CrossRef]

16. Lin, C.F.; Kao, C.H.; Lin, C.Y.; Chen, K.L.; Lin, Y.H. $\mathrm{NH}_{3}$ Plasma-Treated Magnesium Doped Zinc Oxide in Biomedical Sensors with Electrolyte-Insulator-Semiconductor (EIS) Structure for Urea and Glucose Applications. Nanomaterials 2020, 10, 583. [CrossRef]

17. Lin, C.F.; Kao, C.H.; Lin, C.Y.; Liu, C.S.; Liu, Y.W. Comparison Between Performances of $\mathrm{In}_{2} \mathrm{O}_{3}$ and $\mathrm{In}_{2} \mathrm{TiO}_{5}$-Based EIS Biosensors Using Post Plasma $\mathrm{CF}_{4}$ Treatment Applied in Glucose and Urea Sensing. Sci. Rep. 2019, 9, 3078. [CrossRef] [PubMed]

18. Lin, Y.-T.; Luo, J.-D.; Chiou, C.-C.; Yang, C.-M.; Wang, C.-Y.; Chou, C.; Lai, C.-S. Detection of KRAS mutation by combination of polymerase chain reaction (PCR) and EIS sensor with new amino group functionalization. Sens. Actuators B Chem. 2013, 186, 374-379. [CrossRef]

19. Nag, M.; Muller, R.; Steudel, S.; Smout, S.; Bhoolokam, A.; Myny, K.; Schols, S.; Genoe, J.; Cobb, B.; Kumar, A.; et al. Lowtemperature formation of source-drain contacts in self-aligned amorphous oxide thin-film transistors. J. Inf. Disp. 2015, 16, 111-117. [CrossRef]

20. Lu, H.; Zhou, X.; Liang, T.; Zhang, L.; Zhang, S. Oxide Thin-Film Transistors With IMO and IGZO Stacked Active Layers for UV Detection. IEEE J. Electron Devices Soc. 2017, 5, 504-508. [CrossRef]

21. Oh, S.-I.; Choi, G.; Hwang, H.; Lu, W.; Jang, J.-H. Hydrogenated IGZO Thin-Film Transistors Using High-Pressure Hydrogen Annealing. IEEE Trans. Electron Devices 2013, 60, 2537-2541. [CrossRef]

22. Peng, H.; Chang, B.; Fu, H.; Yang, H.; Zhang, Y.; Zhou, X.; Lu, L.; Zhang, S. Top-Gate Amorphous Indium-Gallium-ZincOxideThin-Film Transistors With Magnesium Metallized Source/Drain Regions. IEEE Trans. Electron Devices 2020, 67, 1619-1624. [CrossRef]

23. Kao, C.H.; Liu, C.S.; Lu, S.H.; Tsai, S.C.; Chan, W.L.; Lin, B.H.; Lin, C.F.; Chen, H.; Han, J. Multianalyte Mg-Doped InGaZnO Electrolyte-Insulator-Semiconductor Biosensors and Multiple Material Characterizations of Membrane Nanostructures. IEEE Sens. J. 2020, 20, 10653-10663. [CrossRef]

24. Qian, S.-B.; Shao, Y.; Liu, W.-J.; Zhang, D.W.; Ding, S.-J. Erasing-Modes Dependent Performance of a-IGZO TFT Memory With Atomic-Layer-Deposited Ni Nanocrystal Charge Storage Layer. IEEE Trans. Electron Devices 2017, 64, 3023-3027. [CrossRef] 
25. Sangwook, K.; Jaechul, P.; Changjung, K.; Ihun, S.; Sunil, K.; Sungho, P.; Huaxiang, Y.; Hyung-Ik, L.; Eunha, L.; Youngsoo, P.

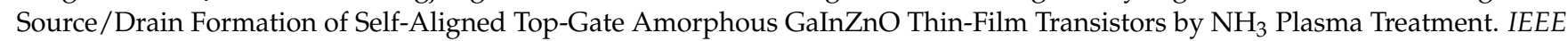
Electron Device Lett. 2009, 30, 374-376. [CrossRef]

26. Tang, H.; Li, Y.; Sokolovskij, R.; Sacco, L.; Zheng, H.; Ye, H.; Yu, H.; Fan, X.; Tian, H.; Ren, T.L.; et al. Ultra-High Sensitive NO 2 Gas Sensor Based on Tunable Polarity Transport in CVD-WS 2 /IGZO p-N Heterojunction. ACS Appl. Mater. Interfaces 2019, 11, 40850-40859. [CrossRef]

27. Bousse, L.; De Rooij, N.F.; Bergveld, P. Operation of chemically sensitive field-effect sensors as a function of the insulator-electrolyte interface. IEEE Trans. Electron Devices 1983, 30, 1263-1270. [CrossRef]

28. Fung, C.D.; Cheung, P.W.; Ko, W.H. A generalized theory of an electrolyte-insulator-semiconductor field-effect transistor. IEEE Trans. Electron Devices 1986, 33, 8-18. [CrossRef]

29. an Hal, R.E.G.; Eijkel, J.C.T.; Bergveld, P. A novel description of ISFET sensitivity with the buffer capacity and double-layer capacitance as key parameters. Sens. Actuators B Chem. 1995, 24, 201-205. [CrossRef]

30. Lu, L.; Zhang, L.; Zhang, X.; Wu, Z.; Huan, S. A MgO nanoparticles composite matrix-based electrochemical biosensor for hydrogen peroxide with high sensitivity. Electroanalysis 2010, 22, 471-477. [CrossRef]

31. Gall, D.; Shin, C.S.; Spila, T.; Odén, M. Growth of single-crystal CrN on MgO (001): Effects of low-energy ion-irradiation on surface morphological evolution and physical properties. J. Appl. Phys. 2002, 91, 3589-3597. [CrossRef]

32. Habibah, Z.; Yusof, K.A.; Ismail, L.N. Sol-gel derived nano-magnesium oxide: Influence of drying temperature to the dielectric layer properties. In IOP Conference Series: Materials Science and Engineering; IOP Publishing: Bristol, UK, 2013; Volume 46, p. 012006.

33. Wang, D.; Huang, Y.; Huo, Z.; Chen, L. Synthesize and electrochemical characterization of Mg-doped Li-rich layered $\mathrm{Li}\left[\mathrm{Li}_{0.2} \mathrm{Ni}_{0.2} \mathrm{Mn}_{0.6}\right] \mathrm{O}_{2}$ cathode material. Electrochim. Acta 2013, 107, 461-466. [CrossRef]

34. Oldham, K.B. A Gouy-Chapman-Stern model of the double layer at a (metal)/(ionic liquid) interface. J. Electroanal. Chem. 2008, 613, 131-138. [CrossRef]

35. Yang, C.-M.; Wang, J.-C.; Chiang, T.-W.; Lin, Y.-T.; Juan, T.-W.; Chen, T.-C.; Shih, M.-Y.; Lue, C.-E.; Lai, C.-S. Nano-IGZO layer for EGFET in pH sensing characteristics. In Proceedings of the 2013 IEEE 5th International Nanoelectronics Conference (INEC), Singapore, 2-4 January 2013; pp. 480-482.

36. Jan, S.-S.; Chen, Y.-C.; Chou, J.-C.; Jan, P.-J.; Cheng, C.-C. Preparation and properties of hydrogen ion-sensitive field effect transistors with sol-gel-derived Mg-modified lead titanate gate. J. Non-Cryst. Solids 2003, 332, 11-19. [CrossRef]

37. Quan, Z.; Liu, X.; Qi, Y.; Song, Z.; Qi, S.; Zhou, G.; Xu, X. Robust room temperature ferromagnetism and band gap tuning in nonmagnetic Mg doped ZnO films. Appl. Surf. Sci. 2017, 399, 751-757. [CrossRef] 